\title{
Role of social media in COVID-19 pandemic
}

\section{Seham Ahmed Fouad ${ }^{1}$, Ghaleb, Alaa Ahmed ${ }^{2}$}

${ }^{1}$ Department of Public Health and Community Medicine, Sohag University, Sohag, Egypt

${ }^{2}$ Department of Internal Medicine, Sohag university, Sohag, Egypt

Tel : 01013594007 Email : sehamghalib85@gmail.com

\begin{abstract}
Background: Social media platforms are among the foremost widely used sources of data within the world, the straight forward and cheap access to the web and an outsized number of registered users in these platforms make them one among the simplest and best ways to disseminate information. During major events, the general response is typically a greater look for information be it a sports event, a disease, or a natural disaster. an honest example are often seen with the height of searches for information on the web and social media platforms in China preceding the height of incidence in COVID-19 cases by 10-14 days, with which Internet and social media networks searches have a demonstrated correlation with the incidence of disease $(1,2)$. Social media platforms have also become helpful for the lay public to take care of communication with friends and family to scale back isolation and tedium which are related to anxiety and long-term distress, therefore becoming a crucial recommendation for isolation reception to assist to scale back the psychological impact (3). Aim of work: Explain the role of social media in COVID-19 pandemic Methods: We reviewed the previously published literature about the topic and also studies Results: we have found several effects for social media on the public will be mentioned in the following review of literature
\end{abstract}

Keywords: COVID-19, Pandemic, Social media

\section{INTRODUCTION:}

Social media platforms are among the foremost widely used sources of data within the world, the straight forward and cheap access to the web and an outsized number of registered users in these platforms make them one among the simplest and best ways to disseminate information. During major events, the general response is typically a greater look for information be it a sports event, a disease, or a natural disaster. an honest example are often seen with the height of searches for information on the web and social media platforms in China preceding the height of incidence in COVID-19 cases by 10-14 days, with which Internet and social media networks searches have a demonstrated correlation with the incidence of disease $(1,2)$.

Social media platforms have also become helpful for the lay public to take care of communication with friends and family to scale back isolation and tedium which are related to anxiety and long- term distress, therefore becoming a crucial recommendation for isolation reception to assist to scale back the psychological impact (3). A number of the foremost relevant characteristics of social media platforms during this pandemic have been the rapid dissemination of protocols at regional, national, and international levels. Sharing protocols about treatment, personal protection equipment, or maybe proposals for fair allocation in scarce medical resource settings have now become the new normal (4).

\section{Advantages of social media use:}

Social media have the good advantage of rapid dissemination of educational content within the COVID-19 era, for instance, Chan et al. (6) developed an info

Received : 24-9-2020

Accepted : 5-10-2020

Online publication : 10-10-2020 
graphic about airway management of patients with suspected or confirmed COVID-19. It had been shared through Twitter and WeChat, during a few days requests were received for its translation into quite ten languages, besides the distribution allowed adapting the info graphic to the particularities of every healthcare setting. Faster dissemination of data regarding preventive measures features a lot of potentials.

A recent study by Basch et al. (7) evaluated the 100 most viewed videos on YouTube with the word "coronavirus", these together had quite 165 million views as of March 5, 2020, 85\% of them belonging to news channels; it had been found that but $1 / 3$ of the videos mentioned the recommended prevention measures, but half mentioned the foremost frequent symptoms, however, almost $90 \%$ commented on deaths, anxiety, and therefore the quarantine status.

This study leaves us with a crucial reflection on the missed opportunities for dissemination of quality information on the prevention of contagion and frequent symptomsof COVID-19 on platforms like YouTube, which are being increasingly consulted as an information source. When it involves publications, studies have shown that the dissemination of scientific literature on social media platforms (Facebook, Twitter, etc.) increases the amount of downloads, queries, and citations of those articles (810) which, with the COVID-19 pandemic are characteristics that have undoubtedly allowed rapid dissemination of data worldwide, additionally to markedly reduced editorial times, which have gone from months of processing to days or weeks since its reception. For this reason, before sharing medical information. Another advantage of social media platforms during the COVID-19 pandemic has been the likelihood of arranging collaborative research projects, surveys, and multi-center studies. Finally, another advantage of social media platforms is supporting continued medical education through online live and recorded webinars through platforms like YouTube, Skype, or Zoom.

\section{Disadvantages of social media use:}

Among the disadvantages, we've the likelihood that information transmitted isn't current, has not been subjected to see review, and is invalid, incorrect, not applicable to our surroundings, or maybe false. Another big obstacle for social media and therefore the dissemination of data are the "bubble filters", an idea coined by Eli Pariser in 2011 (11), which tells us a few "personalized ecosystem" towards the user, during which the algorithms through the info collected from an equivalent user, predict their preferences and yield results that are considered almost like the likes of that user. These bubbles produce a loop of comparable content that forestalls the user from seeing other different sources to contrast information (12).

This idea applies to any scenario or illness that's consulted in internet search engines or on social media platforms like Facebook and Twitter. Finally, probably the worst face of social media is that the potential to disseminate erroneous, alarmist, and exaggerated information which will cause fear, stress, depression, and anxiety in people with or 
without underlying psychiatric illnesses. A study by Wang et al. (13) in China, conducting a web survey with 1,210 responses, found that $53.8 \%$ of respondents considered the epidemic's psychological impact as moderate or severe; even a search group created and validated a scale called "Fear of COVID19 scale" (14) to assess the extent of stress and anxiety within the population and to determine appropriate

measures to stop sequels associated, like post-traumatic stress disorder (PTSD) which was the foremost prevalent psychiatric sequelae after the Severe Acute Respiratory Syndrome (SARS) epidemic in Asia in 2003, followed by depressive disorders (15). Other more severe diseases or events like suicides have already been reported in some parts of the planet like India, Britain, Germany, and Italy (16).

\section{Infodemic and disinformation:}

By April 30, 2020, there have been quite 8,000 papers in PubMed with the word "COVID-19" (17), which tells us about the tsunami of data in but 4 months since its appearance in China; with all the eye poured into the media, the avalanche of knowledge becomes unaffordable, something also called "Infodemia" (18, 19). On the opposite hand, at an equivalent speed information travels, disinformation does, it's for this same reason that some authors have suggested creating working groups aimed toward fighting myths and disinformation in social media platforms (20). during this way, World Health Organization (WHO) developed an exclusive section on its website designed for coronavirus myth-busting (21).
Connected with this same issue, the lay public gains access to preliminary and in vitro study results through newscasts practically at an equivalent time that this information is out there to the medical profession, which combined with the generalized fear of the virus and healthcare systems overwhelmed, generates pressure on patients to demand such experimental treatments for themselves or their families, and doctors may feel compelled to undertake them, even when there's no high-quality evidence to support their use for these purposes.

\section{ABBREVIATIONS}

PTSD: post-traumatic stress disorder

SARS: Severe Acute Respiratory

Syndrome

WHO: World Health Organization

\section{REFERENCES:}

1. Abd-Alrazaq A, Alhuwail D, Househ M, Hamdi M, Shah Z. Top Concerns of Tweeters During the COVID-19 Pandemic: Infoveillance Study. J Med Internet Res. 2020; 22:e19016.

2. Li C, Chen LJ, Chen X, Zhang M, Pang CP, Chen H. Retrospective analysis of the possibility of predicting the COVID-19 outbreak from Internet searches and social media data, China, 2020. Euro Surveill. 2020; 25:2000199.

3. Brooks SK, Webster RK, Smith LE, Woodland L, Wessely S, Greenberg N, et al. The psychological impact of quarantine and how to reduce it: rapid review of the evidence. Lancet. 2020; 395:912-20.

4. Emanuel EJ, Persad G, Upshur R, Thome B, Parker M, Glickman A, et al. Fair Allocation of Scarce Medical Resources in the Time of Covid-19. N Engl J Med. 2020; 382:20492055.

5. Chan AKM, Nickson CP, Rudolph JW, Lee A, Joynt GM. Social media for rapid knowledge dissemination: early experience from the COVID-19 pandemic. Anaesthesia. 2020. Epub ahead of print. 7. Basch $\mathrm{CH}$, Hillyer GC, Meleo-Erwin ZC, Jaime C, 
Mohlman J, Basch CE. Preventive Behaviors Conveyed on YouTube to Mitigate Transmission of COVID-19: Cross-Sectional Study. JMIR Public Health Surveill. 2020; 6:e18807. Erratum in: JMIR Public Health Surveill. 2020; 6:e19601.

6. Eysenbach G. Can tweets predict citations? Metrics of social impact based on Twitter and correlation with traditional metrics of scientific impact. J Med Internet Res. 2011; 13:e123.

7. Allen HG, Stanton TR, Di Pietro F, Moseley GL. Social media release increases dissemination of original articles in the clinical pain sciences. PLoS One. 2013; 8:e68914.

8. Teoh JY, Mackenzie G, Tortolero L, Rivas JG. Social Media Analytics: What You Need to Know as a Urologist. Eur Urol Focus. 2020; 6:434-6.

9. Pariser E. The filter bubble: what the Internet is hiding from you. New York: Penguin Press; 2011; p. 294.

10. Holone $\mathrm{H}$. The filter bubble and its effect on online personal health information. Croat Med J. 2016; 57:298- 301.

11. Wang C, Pan R, Wan X, Tan Y, Xu L, Ho CS, et al. Immediate Psychological Responses and Associated Factors during the Initial Stage of the 2019 Coronavirus Disease (COVID-19) Epidemic among the General Population in China. Int J Environ Res Public Health. 2020; 17:1729.

12. Ahorsu DK, Lin CY, Imani V, Saffari M, Griffiths MD, Pakpour AH. The Fear of COVID-19 Scale: Development and Initial Validation. Int J Ment Health Addict. 2020: 19.

13. Mak IW, Chu CM, Pan PC, Yiu MG, Chan VL. Long-term psychiatric morbidities among SARS survivors. Gen Hosp Psychiatry. 2009; 31:318-26.

14. Thakur V, Jain A. COVID 2019-suicides: A global psychological pandemic. Brain Behav Immun. 2020: S0889-1591;30643-7.

15. PubMed Search. covid-19 - Search Results [Internet]. PubMed. Available at. . Accessed: April 20, 2020.

16. Zarocostas J. How to fight an infodemic. Lancet. 2020; 395:676.

17. Hua J, Shaw R. Corona Virus (COVID-19) "Infodemic" and Emerging Issues through a Data Lens: The Case of China. Int J Environ Res Public Health. 2020; 17:2309.
18. Depoux A, Martin S, Karafillakis E, Preet $\mathrm{R}$, Wilder-Smith A, Larson H. The pandemic of social media panic travels faster than the COVID-19 outbreak. J Travel Med. 2020; 27:taaa031.

19. UN tackles 'infodemic' of misinformation and cybercrime in COVID-19 crisis. United Nations. [Internet]. Available at. . Accessed March 31, 2020. 